\title{
Profile Matching Untuk Perangkingan Pengemudi Taksi Terbaik Pada PT Blue Bird Group
}

\author{
Achmad Munawar \\ Universitas Bina Sarana Informatika \\ achmad.amw@bsi.ac.id
}

\begin{abstract}
Cara Sitasi: Munawar, A. (2019, Maret). Profile Matching Untuk Perangkingan Pengemudi Taksi Terbaik Pada PT Blue Bird Group. (S. Dalis, Ed.) Paradigma - Jurnal Komputer dan Informatika, 21(1), 133-136. doi: $10.31294 /$ p.v21i1.5362
\end{abstract}

\begin{abstract}
Decision Support System was created to support and complete the stages in the decision-making in an organization of companies, especially in the management of the associated start of the phase of identifying problems, selecting the data that is relevant and competent and also determine the approach used in the process decision to evaluate the selected alternatives exist. Decision Support System is used in this research is the Profile Matching method. In the Profile Matching method, there are several phases of calculation for each candidate will be ranked, from the grouping of each profile and its attributes into the field of assessment, until the final calculation, to be obtained the total value of the end of each candidate, And the ranked will be based on the highest value to lowest value, in which the highest value of each candidate having the greatest opportunities. In the case study here the researchers took a case study for the Blue Bird taxi driver in PT Blue Bird Group Pool Raden inten. This method is expected to assist the management in the process of ranking the best taxi drivers and provide the most appropriate decision and as fairly as unfair for the taxi drivers.
\end{abstract}

Keywords: Dicision Support System, Profile Matching, Ranking

\section{PENDAHULUAN}

Banyaknya pelayanan pengemudi taksi yang kurang memuaskan konsumen membuat munculnya banyak tanggapan yang menuding pihak manajemen angkutan umum khususnya manajemen angkutan umum taksi kurang memperhatikan kesejahteraan dan kinerja para pengemudinya. Model manajemen operasional angkutan umum taksi baik yang menggunakan sistem setoran maupun yang menggunakan sistem komisi lebih mengutamakan banyaknya uang yang disetorkan oleh pengemudi kepada pihak perusahaan. Faktor tersebut akan membuat pengemudi taksi hanya berfikir bagaimana cara mencari penumpang sebanyak banyaknya untuk kejar penghasilan tanpa memperhatikan faktor kenyamanan dan keamanan konsumen. Hal ini dapat mengakibatkan menurunnya pelayanan pengemudi terhadap konsumen yang bisa mengakibatkan turunnya rasa kepercayaan dan loyalitas konsumen terhadap perusahaan taksi tersebut Untuk itu PT Blue Bird Group dalam menuju peningkatan pelayanan kepada penumpang telah merencanakan perubahan penilaian terhadap pengemudi berprestasi yang tidak hanya berdasarkan penghasilan pengemudi tetapi juga berdasarkan faktorfaktor yang berkaitan dengan pelayanan yang nyaman dan aman.

Pemberian insentif kepada pengemudi yang berprestasi ini terbukti sangat berpengaruh dalam motivasi dan semangat kerja pengemudi taksi dalam melakukan perubahan pelayanan terhadap konsumen, terutama bagi perusahaan taksi yang menggunakan sistem komisi seperti pada perusahaan taksi PT Blue Bird Group.

Menurut Filippo dalam (Triana,2012) Motivasi adalah suatu keterampilan dalam memadukan kepentingan karyawan dan kepentingan organisasi, sehingga keinginan-keinginan karyawan dipuaskan secara bersamaan dengan tercapainya sasaran-sasaran organisasi. Metode untuk membangkitkan motivasi melalui kemampuan diri sendiri sering disebut self management, yaitu manajemen fisik, manajemen intelektual, manajemen rohani, manajemen emosi, dan manajemen konflik.

Dessler dalam (Triana, 2012) Motivasi terjadi pada saat karyawan melihat adanya insentif atau ganjaran yang dapat memenuhi kebutuhan yang timbul.Keputusan terjadi apabila ada hambatan diantara karyawan tersebut dengan adanya insentif dan ganjaran.

Evaluasi kinerja pengemudi menjadi hal yang rumit ketika tidak ada standarisasi.Penilaian pengemudi berprestasi, selama ini hanya mengandalkan pada penilaian penghasilan pengemudi saja. Dan ini terasa kurang adil bagi pengemudi-pengemudi yang telah melakukan pelayanan secara maksimal kepada pelanggan walau penghasilannya tidak maksimal.

Berdasarkan pada latar belakang diatas maka peneliti mengajukan model evaluasi pengemudi dengan jalan perangkingan menggunakan Decision Support System (DSS) dengan metode profile Matching. Rancangan DSS dengan metode Profile Macthing ini diharapkan 
bisa memberikan solusi yang paling tepat karena memiliki fitur multi-atribut untuk menentukan nilainilai dari tidakan terbaik dari sebuah himpunan tindakan dengan jalan dibuatkan sistem perankingan dan pihak manajemen dapat memberikan insentif dan penghargaan kepada pengemudi tersebut seadiladilnya dan dapat mendorong pengemudi agar memberikan pelayanan terbaik kepada konsumen.

\section{Konsep Dasar Decision Support System (DSS)}

Konsep Decision Support System (DSS) atau Sistem Penunjang Keputusan (SPK) pertama kali digunakan pada awal tahun 1970 oleh Michael S. Scott Morton dengan menggunakan istilah "management decision system". Konsep ini merupakan sebuah mekanisme yang berbasis pada penggunaan data dan model untuk memecahkan permasalahan-permasalahan yang tidak terstruktur. Sesuai definisi tersebut, DSS berbasis pada tiga kata kunci, yaitu data, model, dan permasalahan tidak terstruktur.

(Raymond McLeod, Jr, 2010) Dalam bukunya Sistem Informasi Manajemen menekankan bahwa Sistem Pendukung Keputusan adalah suatu sistem informasi yang ditujukan untuk membantu manajemen dalam memecahkan masalah yang dihadapinya.

\section{Profile Matching}

Profile matching merupakan suatu proses yang sangat penting dalam manajemen SDM dimana terlebih dahulu menentukan kriteria-kriteria yang diperlukan dalam kasus ini adalah pengemudi. Dalam Profile Matching pegawai yang bisa dipromosikan untuk menduduki suatu jabatan (kenaikan jabatan) adalah pegawai yang paling mendekati profil ideal (Ekasari, 2010).

Penelitian yang dilakukan oleh Jozua F. Palandi dan Zusana E. Pudyastuti, (2010) tentang Penyaringan Kandidat Untuk Promosi Jabatan, dengan Profile Matching. Dalam penelitian ini Jozua F. Palandi, Zusana E. Pudyastuti, tidak manambahkan beberapa aspek atau atribut di tiap-tiap kriteria, walau masih ada aspek-aspek lain yang cukup penting untuk bisa ditambahkan sebagai dasar perhitungan nilai akhir untuk menyaring dan menyeleksi para kandidatnya.

Penelitian yang dilakukan oleh Moh. Muthohir dan Vincent Suhartono, (2013) tentang penentuan rangking calon penerima beasiswa menggunakan fuzzy query pada database, dalam penelitian ini perangkingan dihitung dengan fuzzy query yang diterapkan dalam aplikasi database.

Adapun penelitian yang dilakukan oleh Ferdian Benny Udyana (2011) dari Universitas Komputer Indonesia mengenai metode profile matching untuk perencanaan karir dan pemilihan karyawan berprestasi pada $\mathrm{CV}$. SAS BANDUNG. Sistem ini bertugas untuk melakukan analisis terhadap karyawan yang menurut perhitungan cocok dengan kriteria untuk pengisian jabatan yang kosong dan akan menghasilkan ukuran kompetensi antar karyawan dengan jabatan berdasarkan spesifikasi yang jelas.

\section{METODOLOGI PENELITIAN}

\section{Metode Penelitian}

Penelitian ini adalah penelitian eksperimen dengan metode sebagai berikut:

a. Penentuan Masalah

Penentuan masalah penelitian dengan menggunakan studi literatur dan studi lapangan terhadap hal-hal yang terkait.

b. Penentuan computing approach

Untuk menyelesaikan permasalahan maka berdasarkan studi literatur terhadap beberapa computing approach, maka sistem rekomendasi dengan menggunakan metode DSS dengan profile matching merupakan pendekatan yang terbaik untuk masalah tersebut.

\section{Metode Pengumpulan Data}

Dalam penelitian ini metode pengumpulan data sebagai berikut :

a. Data sekunder

Data sekunder diperoleh secara tidak langsung bersumber dari dokumentasi, literatur, buku, jurnal dan informasi lainnnya yang ada hubungannya dengan masalah yang diteliti.

b. Data primer

Data primer diperoleh dari data hasil uji perhitungan dan perbandingan hasil untuk mengukur keakuratannya.

\section{HASIL DAN PEMBAHASAN}

\section{Menentukan Profile}

Sistem perangkingan hasil kinerja pengemudi dengan DSS Frofile Matching ini, akan dilakukan dalam sebuah studi kasus tentang seleksi perangkingan pengemudi terbaikdi pool RD yang berlokasi di Duren sawit jakarta Timur.Studi kasus ini mengambil sampel yang berjumlah 10 orang pengemudi, dimana perangkingan didasarkan atas beberapa aspek dari ProfileTeknis yaitu:

1. Penghasilan

2. Kecepatan

3.Konsisten

4.Keandalan

5.Masa Kerja

Kemudian aspek-aspek dari ProfileTeknis tersebut dibagi menjadi 2 bagian untuk proses perhitungannya, yaitu : Core Factor (Faktor Utama) dan Secondary factor (Faktor Kedua). Pengelompokan dari masingmasing aspek Profile Teknis ini dapat dilihat pada tabel dibawah ini.

Tabel 1. Pengelompokan Aspek-aspek

\begin{tabular}{ll}
\hline Keterangan & Teknis \\
\hline Core Factor & Penghasilan (Pen) \\
& Kecepatan (Kec) \\
& Konsisten (Kon) \\
Secondary Factor & Keandalan (Kea) \\
\hline
\end{tabular}


Masa Kerja (Mas)

\section{Perhitungan Pemetaan Gap Per Profile}

Perhitungan gap disini adalah selisih antara nilai Profile pengemudi dengan nilai Profile acuan (PA) atau dapat ditunjukkan pada rumus berikut :

Gap = Profile pengemudi-Profile acuan

Untuk pengumpulan gap-gap pada tiap-tiap aspek dalam Profile Teknis mempunyai perhitungan yang berbeda-beda. Pada perhitungan ini, gap antara nilai pengemudi dengan nilai acuan untuk masing-masing aspeknya dimana dalam Profile Teknis ini berjumlah 5 aspek, kemudian gap-gap tersebut dikumpulkan menjadi 1 tabel yaitu : field (-), untuk menempatkan jumlah dari nilai gap yang bernilai negative dan field(+), untuk menempatkan jumlah dari nilai gap yang bernilai positif. Seperti dapat dilihat pada tabel 2:

Tabel 2. Perhitungan Gap pada Profile Teknis

\begin{tabular}{|c|c|c|c|c|c|c|c|c|}
\hline No & NIP & $\mathbf{P e}$ & $\mathrm{Ke}$ & Kon & Kea & Mas & \multicolumn{2}{|c|}{ GAP } \\
\hline 1 & 10399 & 3 & 4 & 3 & 4 & 4 & & \\
\hline 2 & 31887 & 4 & 3 & 2 & 3 & 3 & & \\
\hline 3 & 34311 & 3 & 5 & 4 & 3 & 3 & & \\
\hline 4 & 49017 & 4 & 3 & 4 & 4 & 3 & & \\
\hline 5 & 51843 & 5 & 4 & 4 & 3 & 3 & & \\
\hline 6 & 54023 & 5 & 5 & 3 & 3 & 3 & & \\
\hline 7 & 55147 & 4 & 5 & 4 & 5 & 3 & & \\
\hline 8 & 56213 & 3 & 4 & 4 & 4 & 3 & & \\
\hline 9 & 59400 & 5 & 5 & 4 & 4 & 3 & & \\
\hline 10 & 64574 & 5 & 5 & 4 & 4 & 2 & & \\
\hline & PA & 5 & 5 & 5 & 4 & 4 & $(-)$ & $(+)$ \\
\hline 1 & 10399 & -2 & -1 & -2 & 0 & 0 & -5 & 0 \\
\hline 2 & 31887 & -1 & -2 & -3 & -1 & -1 & -8 & 0 \\
\hline 3 & 34311 & -2 & 0 & -1 & -1 & -1 & -5 & 0 \\
\hline 4 & 49017 & -1 & -2 & -1 & 0 & -1 & -5 & 0 \\
\hline 5 & 51843 & 0 & -1 & -1 & -1 & -1 & -4 & 0 \\
\hline 6 & 54023 & 0 & 0 & -2 & -1 & -1 & -4 & 0 \\
\hline 7 & 55147 & -1 & 0 & -1 & +1 & -1 & -3 & +1 \\
\hline 8 & 56213 & -2 & -1 & -1 & 0 & -1 & -5 & 0 \\
\hline 9 & 59400 & 0 & 0 & -1 & 0 & -1 & -2 & 0 \\
\hline 10 & 64574 & 0 & 0 & -1 & 0 & -2 & -3 & 0 \\
\hline
\end{tabular}

Pada tabel 2. dapat dilihat bahwa nilai Profile Acuan (PA) untuk tiap-tiap aspek yang tertera dalam tabel tersebut adalah sebagai berikut : Penghasilan $($ Pen $)=$ 5, Kecepatan $(\mathrm{Kec})=5$, Konsisten $($ Kon $)=5$, Keandalan $($ Kea $)=4$, dan Masa Kerja $($ Mas $)=4$. Kemudian sebagai contoh, diambil salah satu pengemudi dengan NIP 10399 dimana nilai-nilai aspeknya adalah :Penghasilan (Pen) = 3, Kecepatan $(\mathrm{Kec})=4$, Konsisten $($ Kon $)=3$, Keandalan $(\mathrm{Kea})=4$, danMasa Kerja $(\mathrm{Mas})=4$. Sehingga hasil gap yang terjadi untuk tiap aspeknya adalah :Penghasilan $(\mathrm{Pen})=-2, \quad$ Kecepatan $\quad(\mathrm{Kec})=-1$, Konsisten $($ Kon $)=-2$, Keandalan $($ Kea $)=0$, dan Masa
Kerja $($ Mas $)=0$. Setelah proses perhitungan ini selesai maka gap-gap tersebut dikumpulkan dalam satu field seperti dapat dilihat pada tabel 2. tersebut. Dalam contoh ini, maka pengemudi tersebut memiliki gap (-) sejumlah -5 . Begitu juga dengan perhitunganperhitungan terhadap kandidat pengemudi yang lainnya.

\section{Pemberian Bobot nilai pada Gap Profile Teknis} Setelah didapatkan nilai pada gap Profile Teknis dari masing-masing pengemudi maka tiap-tiap nilai gap diberi bobot nilai dengan menggunakan tabel bobot nilai dibawah atau pada tabel 3, maka tiap-tiap pengemudi akan memiliki table bobot nilai.

Tabel 3 Bobot nilai Gap

\begin{tabular}{|c|c|c|c|}
\hline No & GAP & Bobot Nilai & Keterangan \\
\hline 1 & 0 & 5 & $\begin{array}{c}\text { Tidak ada Gap (kompetensi } \\
\text { sesuai yang dibutuhkan) }\end{array}$ \\
\hline 2 & 1 & 4,5 & $\begin{array}{c}\text { Kompetensi pengemudi lebih } 1 \\
\text { tingkat }\end{array}$ \\
\hline 3 & -1 & 4 & $\begin{array}{c}\text { Kompetensi pengemudi kurang } \\
1 \text { tingkat }\end{array}$ \\
\hline 4 & 2 & 3,5 & $\begin{array}{c}\text { Kompetensi pengemudi lebih } 2 \\
\text { tingkat }\end{array}$ \\
\hline 5 & -2 & 3 & $\begin{array}{c}\text { Kompetensi pengemudi kurang } \\
2 \text { tingkat }\end{array}$ \\
\hline 6 & 3 & 2,5 & $\begin{array}{c}\text { Kompetensi pengemudi lebih } 3 \\
\text { tingkat }\end{array}$ \\
\hline 7 & -3 & 2 & $\begin{array}{c}\text { Kompetensi pengemudi kurang } \\
3 \text { tingkat }\end{array}$ \\
\hline 8 & 4 & 1,5 & $\begin{array}{c}\text { Kompetensi pengemudi lebih } 4 \\
\text { tingkat }\end{array}$ \\
\hline 9 & -4 & 1 & $\begin{array}{c}\text { Kompetensi pengemudi kurang } \\
4 \text { tingkat }\end{array}$ \\
\hline
\end{tabular}

\section{MenghitungNilaiCore Factordan Seconday Factor}

Dari bobot nilai gap pada tiap-tiap aspek yang terdapat pada Profile Teknis, maka tiap-tiap aspek pada Profile Teknis dibagi menjadi 2 bagian kelompok yaitu kelompok Core Factor dan Secondary Factor dan masing-masing kelompok ini baik Core Factor dan Secondary Factor akan dihitung jumlah dan rata-rata dari bobot nilai per kelompok berdasarkan rumus masing-masing. Hasil bobot nilai gap untuk perhitungan jumlah dan rata-rata core factor dan secondary factor.

\section{Menentukan Nilai Akhir Profile Teknis}

Setelah diketahui nilai Profile Teknis dari masingmasing pengemudi diatas kemudian dihitung nilai total berdasarkan rumus prosentase dari core factor dan secondary factor. Perhitungan dapat dilihat tabel 4. di bawah ini :

Tabel 4.Nilai total dari Profile Teknis

\begin{tabular}{ccccc}
\hline No & NIP & $\begin{array}{c}\text { Core } \\
\text { Factor }\end{array}$ & $\begin{array}{c}\text { Secondary } \\
\text { Factor }\end{array}$ & NI \\
\hline $\mathbf{1}$ & 10399 & 10 & 10 & $(6+4)=10$ \\
$\mathbf{2}$ & 31887 & 9 & 8 & $(5,4+3,2)=8,6$ \\
\hline
\end{tabular}




\begin{tabular}{ccccc}
\hline $\mathbf{3}$ & 34311 & 12 & 8 & $(7,2+3,2)=10,4$ \\
$\mathbf{4}$ & 49017 & 11 & 9 & $(6,6+3,6)=10,2$ \\
$\mathbf{5}$ & 51843 & 13 & 8 & $(7,8+3,2)=11$ \\
$\mathbf{6}$ & 54023 & 13 & 8 & $(7,8+3,2)=11$ \\
$\mathbf{7}$ & 55147 & 13 & 8,5 & $(7,8+3,4)=11,1$ \\
$\mathbf{8}$ & 56213 & 11 & 9 & $(6,6+3,6)=10,2$ \\
$\mathbf{9}$ & 59400 & 14 & 9 & $(8,4+3,6)=12$ \\
$\mathbf{1 0}$ & 64574 & 14 & 8 & $(8,4+3,2)=11,6$ \\
\hline
\end{tabular}

Berdasarkan perhitungan-perhitungan rumus Profile Matching diatas pada tiap-tiap pengemudi hingga akhirnya mendapatkan hasil akhir dari Profile Teknis seperti contoh pada tabel 4, maka dapat ditentukan perankingan dari tiap-tiap pengemudi berdasarkan pada semakin besar nilai hasil akhir tersebut seperti pada tabel 5, dibawah ini :

Tabel 5. Daftar Rangking Pengemudi Terbaik

\begin{tabular}{ccccc}
\hline No & NIP & $\begin{array}{c}\text { Core } \\
\text { Factor }\end{array}$ & $\begin{array}{c}\text { Secondary } \\
\text { Factor }\end{array}$ & NI \\
\hline $\mathbf{1}$ & 59400 & 14 & 9 & 12 \\
$\mathbf{2}$ & 64574 & 14 & 8 & 11,6 \\
$\mathbf{3}$ & 55147 & 13 & 8,5 & 11,1 \\
$\mathbf{4}$ & 54023 & 13 & 8 & 11 \\
$\mathbf{5}$ & 51843 & 13 & 8 & 11 \\
$\mathbf{6}$ & 34311 & 12 & 8 & 10,4 \\
$\mathbf{7}$ & 49017 & 11 & 9 & 10,2 \\
$\mathbf{8}$ & 56213 & 11 & 9 & 10,2 \\
$\mathbf{9}$ & 10399 & 10 & 10 & 10 \\
$\mathbf{1 0}$ & 31887 & 9 & 8 & 8,6 \\
& & & & \\
\hline
\end{tabular}

Dari hasil perangkingan akhir untuk mendapatkan urutan nilai pengemudi terbaik Ini seperti pada tabel 5 . diatas diharapkan akan membantu serta memberikan masukan kepada pihak manajemen terkait untuk bisa menentukan siapa yang paling tepat untuk menjadi pengemudi terbaik, paling teladan dan berprestasi, dan begitu pula sebaliknya berdasarkan urutan perangkingan tersebut.

\section{KESIMPULAN}

Penerapan DSS dengan metode Profile Matching pada sistem perangkingan untuk pengemudi berprestasi memberikan hasil yang berbeda dari pada menggunakan sistem sebelumnya yang hanya berdasarkan penghasilan pengemudi, hal ini dikarenakan pada perhitungan DSS dengan metode Profile Matching diperlukan lebih dari satu aspek pada Profile Teknisnya. Dan tiap-tiap aspek akan dihitung gap-gapnya dari nilai acuan yang dikehendaki oleh pihak manajemen. Gap-gap tersebut kemudian diberikan bobot nilai, dan bobot nilai dari gap-gap pada tiap-tiap aspek tersebut dikelompokan menjadi 2 yaitu core factor dan secondary factor, yang mana core facktor dan seconday factor mempunya bobot nilai prosentase yang berbeda.
Hal inilah yang membuat metode ini mempunyai kelebihan yaitu tingkat subyektifitas dari masingmasing pengemudi dan pengambilan keputusan dapat diakomodasi. Dan dari proses ini akan menghasilkan hasil akhir yang lebih adil bagi pengemudi dimana ini akan mendorong pengemudi tidak hanya mengejar penghasilan semata tetapi juga mengedepankan faktorfaktor yang berkaitan dengan pelayanan dan keamanan penumpang.

Untuk mengembangkan metode DSS ini kedepan dan perbandingan dengan Metode-metode lainnya perlu adanya kajian khusus tentang metode DSS ini dengan mencoba pada beberapa kasus dimana dalam kasus tersebut terdapat banyak sekali nilai subyektivitasnya.

\section{REFERENSI}

Beerawa, I.N.E., Sutanto, T. \& Susilo, T.H. (2012). Rancang Bangun Sistem Pendukung Keputusan Seleksi Tenaga Kerja Dengan Metode Profile Matching (Studi Kasus PT. Adhi Karya (Persero), Tbk Divisi Konstruksi VII).Jurnal Sistem Informasi \& Komputer Akuntansi (JSIKA) 1(1): 1-13.

Dwijaya, I.F. (2010). Sistem Pendukung Keputusan Kenaikan Jabatan pada PT. SYSMEXMenggunakan MetodeProfile Matching.Skripsi.Universitas Komputer Indonesia.

Hamzah, Sutoyo \& Mudjihartono, P. (2010). Sistem Pendukung Keputusan Kinerja Dosen dengan Metode Balanced Scorecard(Studi Kasus: UniversitasRespati Yogyakarta). Seminar Nasional Informatika (semnasIF)UPN "Veteran" Yogyakarta, pp. E82 - E90.

Woro Mardikawati, Naili Farida, 2013. Pengaruh Nilai Pelanggan dan Kualitas Layananterhadap Loyalitas Pelanggan, Melalui Kepuasan Pelanggan pada Pelanggan BusEfisiensi (studi po efisiensi jurusan yogyakarta-cilacap).Jurnal Administrasi Bisnis, Volume 2, Nomor 1, Maret 2013

\section{PROFIL PENULIS}

Achamd Mnawar lahir di Jakarta pada tanggal 13 Agstus 1973. Sebagai dosen sistem informasi di Universitas BSI mulai dari tahun 2010 sampai dengan saat ini. Menyelesaikan Pendidikan Diploma 3 di Universitas Gunadarma Depok Program Studi Manajemen informatika pada tahun 1996, dan pendidikan Strata 1 di STMIK MH Thamrin Jakarta program studi Sistem Informasi pada tahun 2003 serta Pendidikan Strata 2 pada tahun 2015 di Pascasarjana STMIK Nusa Mandiri Jakarta program studi Sistem Informasi Manajemen. 